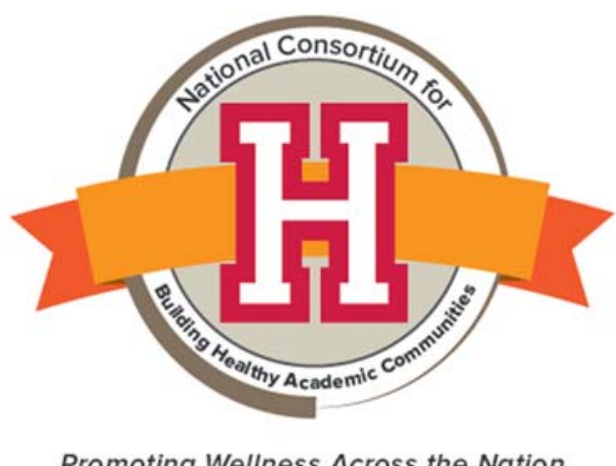

\title{
National Consortium for Building Healthy Academic Communities Position Paper College Student Mental Health
}

\author{
Marcelle Holmes, PhD \\ The University of California, Irvine
}

Submitted 22 September 2017: accepted 20 October 2017

Keywords: college mental health, student mental health, mental health recommendations

The fall 2016 National College Health Assessment surveyed 33,512 undergraduate and graduate students from around the country (American College Health Association, 2017) on attitudes toward mental health. Some 10.4\% of respondents had "seriously considered suicide" within the last 12 months. More than 60\% of students had felt "overwhelming anxiety" within the past 12 months and $38.2 \%$ felt "so depressed that it was difficult to function" at some time in the previous 12 months. Students reported being treated for a number of psychological issues, including anxiety (19.1\% of respondents), depression (15.2\%), ADHD (6.1\%), panic attacks (9.6\%), and insomnia $(4.9 \%)$.

The Association for University and College Counseling Center Directors' recent Annual Survey reveals that $57.1 \%$ of counseling center directors believed that the severity of student mental health concerns and related behavior on their campuses had risen (Reetz, Bershad, LeViness, \& Whitlock, 2016). Anxiety and depression topped the list of presenting concerns in their counseling centers, with relationship issues, suicidal thoughts/behaviors, selfinjury, alcohol abuse/dependence, sexual/physical assault and issues of oppression (racism, sexism, homophobia) appearing prominently. Additionally, directors in the national sample reported that more than $16 \%$ of counseling center students had extensive or significant prior treatment histories (Reetz et al., 2016).

A variety of explanations exist for why this generation of students may be experiencing elevated levels of psychological distress. Academic concerns, confusion about their life path and their purpose, the after effects of a rigorous college admissions process, or fears of failure have been cited as concerns (Holterman, 2016). Further, social media may promote unfavorable comparisons with peers. Less stigma in mental help-seeking and advances in pharmacology, which allow individuals who previously would not have been able to attend college to enroll, may have increased numbers of college students with mental health issues (Holterman, 2016). 
Coping with the financial realities of a college education is also stressful for many. With rising student loan obligations and pressures to be fully or partially employed during college and gainfully employed immediately afterwards, many students are experiencing financial stressors that make college a very different environment than it was in previous generations. Additionally, for some racial/ethnic minority, international, first-generation or undocumented students, a new college environment may introduce new stressors, such as overt discrimination, micro aggressions or difficulties obtaining the social capital or opportunity often necessary for success. Further, professors, staff, and peers may make inappropriate comments to Lesbian, Gay, Bisexual, or Transgender (LGBT) students. There may be social and familial pressures associated with coming out; trans students may also face unique concerns associated with the recognition of their gender identity. Student veterans face their own stressors as well, from stigma associated with military service to mental health issues arising from combat or other familial or social stressors. This represents just a handful of potential concerns.

Institutions should be attuned to the mental health needs of their students for a variety of reasons. Not only do disruptions to college attendance based on mental health difficulties negatively impact students and their futures, but they can have a detrimental effect on campus culture and the institution's reputation. Retention rates and recruitment efforts can all be impacted when sufficient attention is not paid to campus mental health services (Kognito, 2015; Gruttadaro \& Crudo, 2012).

\section{RECOMMENDATIONS}

- Adhere to established staffing ratios. The International Association of Counseling Services (IACS) recommends staffing ratios in student counseling centers in the range of one Full Time Equivalent (FTE) professional staff member (excluding trainees) to every 1,000 to 1,500 students, depending on services offered and on other campus mental health agencies (International Association of Counseling Services, 2017). The International Association of Counseling Services (IACS) has determined that the likely consequences of a suboptimal ratio are the following: Larger wait lists which result in a greater likelihood of a student leaving the university, difficulty providing services to students who are experiencing more severe psychological issues, and increased liability risks to the counseling center and the university by not adhering to the standards of the profession. Students whose counseling centers do not adhere to the IACS ratio standards are at a disadvantage as they have increased barriers to the help that might enhance their academic performance. Inadequate ratios prohibit counseling center staff from serving in other ways, such as training faculty and staff, consulting with concerned community members about students in distress, reaching out to student groups, and serving on important university committees. The National Consortium for Building Healthy Academic Communities (NCBHAC) strongly supports this standard.

- Eliminate obstacles that students face in accessing mental health services, such as inconvenient appointment hours, poor confidentiality or high costs (Kognito, 2015). 
- Train faculty, staff and students in mental health symptom recognition in themselves and in others. Train the community on how to reach out to students of concern and how to motivate them to seek help (Kognito, 2015).

- Train faculty and staff to understand that students can be successful with accommodations, and they are expected to respect and enforce necessary accommodations. Consider making these trainings mandatory (Gruttadaro \& Crudo, 2012).

- Provide on-campus accommodations for students receiving treatment (Kognito, 2015).

- Facilitate development or continuation of peer-support groups (Kognito, 2015).

- Include information about mental health resources on the school's official website and on campus materials and events (Kognito, 2015).

- Collaborate with and support student clubs to inform students about available support services and reduce stigma (Kognito, 2015).

- Keep cultural competency as a guiding force in the provision of campus mental health services. Provide trainings for providers about evidence-based approaches to the treatment of marginalized and disadvantaged groups.

\section{ENDORSEMENT}

The National Consortium for Building Health Academic Communities (NCBHAC) is a national organization dedicated to crafting and promoting a comprehensive approach to the health and well-being of students, faculty, and staff. NCBHAC is dedicated to enhancing campus-wide wellness efforts, eliminating silos, and sharing best practices. NCBHAC has created a series of position papers devoted to helping institutions address the urgent health issues of the day. This position statement reflects the views of NCBHAC and serves only as a collection of recommendations and guidelines. The purpose of NCBHAC position papers is to assist academic institutions in creating wellness programming, advocating for resources, enhancing the academic mission of the institution, and getting broad support for wellness efforts. 


\section{REFERENCES}

American College Health Association (2017). American College Health Association-National College Health Assessment II: Reference Group Executive Summary Fall 2016. Hanover, MD: American College Health Association

Gruttadaro, D., \& Crudo, D. (2012). College students speak: A survey report on mental health. Arlington, VA: NAMI

Holterman, A. (2016, August 25). Mental health problems for college students are increasing. [Web article]. Retrieved from http://www.healthline.com/health-news/mental-health-problems-for-college-students-areincreasing-071715\#1

International Association of Counseling Services (2017). Statement regarding recommended staff to student ratios. [Web post]. Retrieved from http://www.iacsinc.org/staff-to-student-ratios.html

Kognito (2015, May). Benefits of investing in students' mental health: White paper. [White paper]. Retrieved from https://www.ocde.us/HealthyMinds/Documents/Landing\%20Page/Return_On_Investment_Mental\%20 Health\%20Kognito_WhitePaper.pdf

Reetz, D. R., Bershad, C., LeViness, P., \& Whitlock, M. (2016). The Association for University and College Counseling Center Directors annual survey [Report]. Retrieved from https://www.aucced.org/assets/documents/auccd $\% 202016 \% 20$ monograph\%20-\%20public.pdf

Address author correspondence to:

Marcelle Holmes, PhD

Associate Vice Chancellor Wellness, Health, and Counseling

University of California, Irvine

Irvine, CA 92697-2215

Marcelle.holmes@uci.edu 